\title{
QUALIDADE ESPACIAL NA HABITAÇÃO: O CASO QUINTA MONROY
}

\author{
ALBANO, Gabriela \\ Instituto de Arquitetura e Urbanismo - USP, e-mail: gabriela.albano@usp.br \\ LONGSDON, Louise \\ Instituto Federal de Mato Grosso - IFMT, e-mail: lovise.logsdon@cba.ifmt.edu.br \\ FABRICIO, Márcio Minto \\ Instituto de Arquitetura e Urbanismo - USP, e-mail: marcio@sc.usp.br
}

\begin{abstract}
RESUMO
Este trabalho, fruto de uma pesquisa de Iniciação Científica, buscou analisar o projeto Quinta Monroy sob a ótica da funcionalidade e flexibilidade das unidades habitacionais. Para isso, em um primeiro momento o projeto foi modelado em BIM no software Autodesk Revit 2019, onde foram exploradas diferentes possibilidades de layout. Posteriormente, após uma vasta revisão bibliográfica, o projeto foi analisado frente aos requisitos que a literatura aponta como essenciais para a garantia de funcionalidade e flexibilidade nas unidades habitacionais. Como fruto dessa análise, tem-se a percepção de um projeto de qualidade e com possíveis adequações às necessidades de seus usuários.
\end{abstract}

Palavras-chave: Flexibilidade, Funcionalidade, Habitação de interesse social.

\begin{abstract}
This work, the result of a research of Scientific Initiation, sought to analyze the Quinta Monroy project from the perspective of the functionality and flexibility of housing units. For this, the project was first modeled in BIM in Autodesk Revit 2019 software, where different layout possibilities were explored. Subsequently, after a large bibliographical review, the project was analyzed against the requirements that the literature points out as essential for guaranteeing functionality and flexibility in housing units. As a result of this analysis, one has the perception of a quality project and with possible adaptations to the needs of its users.
\end{abstract}

Keywords: Flexibility, Functionality, Social housing.

\section{INTRODUÇÃO}

Em contraponto à predominante baixa qualidade da habitação social produzida no Brasil, bons exemplos foram projetados e construídos em alguns países. É o caso do projeto Quinta Monroy, obra de Alejandro Aravena, do escritório Elemental. O projeto partia da ideia de bancar "metade" da moradia e dar ao morador a responsabilidade de construir o restante. As partes que mais demandam recursos, como fundação e estrutura, eram entregues a priori (JARDIM, 2017).

Quinta Monroy apresenta aspectos de flexibilidade e qualidade espacial. Contou com a participação dos moradores no processo projetual e é reconhecido no meio arquitetônico pelos prêmios recebidos. Seu arquiteto recebeu o Pritzker de Arquitetura em 2016 (aU | Arquitetura e Urbanismo, 2016).

ALBANO, G.; LONGSDON, L.; FABRiCIO, M, M. Qualidade espacial na habitação: o caso Quinta Monroy. In: SIMPÓSIO BRASILEIRO DE QUALIDADE DO PROJETO NO AMBIENTE CONSTRUÍDO, 6., 2019, Uberlândia. Anais... Uberlândia: PPGAU/FAUeD/UFU, 2019. p. 1341-1351. DOI https://doi.org/10.14393/sbqp19121 
Frente a isso, este artigo tem como objetivo analisar a qualidade espacial do projeto Quinta Monroy sob a luz dos princípios de funcionalidade e flexibilidade das unidades habitacionais.

Para isso, a pesquisa seguiu três etapas principais: (1) Revisão Bibliográfica Foram levantadas na literatura especializada quais seriam os atributos que conferem qualidade espacial ao projeto, bem como os dados do projeto Quinta Monroy; (2) Modelagem BIM - O projeto foi modelado no software Autodesk Revit 2019, explorando-se as possibilidades de expansão e mobiliamento, utilizando famílias de mobiliário compatíveis com o padrão popular; (3) Análise qualitativa do projeto, através do cruzamento com os requisitos de flexibilidade e funcionalidade encontradas na literatura.

\section{QUALIDADE ESPACIAL DA MORADIA}

Quadro 1 - Diretrizes de funcionalidade para o projeto de HIS

\begin{tabular}{|c|c|c|c|c|c|}
\hline \multicolumn{6}{|c|}{ Diretrizes de funcionalidade } \\
\hline \multicolumn{6}{|c|}{ Prever mobiliário adequado nos ambientes } \\
\hline Sala & Cozinha & Banheiro & Área serv. & Dorm. casal & Dorm. filhos \\
\hline $\begin{array}{l}\text { Sofá } \\
\text { Poltrona } \\
\text { Rack TV } \\
\text { Mesa de } \\
\text { canto ou } \\
\text { centro }\end{array}$ & $\begin{array}{l}\text { Pia com } \\
\text { balcão } \\
\text { Armário } \\
\text { superior } \\
\text { Fogão } \\
\text { Geladeira }\end{array}$ & $\begin{array}{l}\text { Lavatório } \\
\text { Vaso } \\
\text { sanitário } \\
\text { Box/chuveiro }\end{array}$ & $\begin{array}{l}\text { Tanque } \\
\text { Máquina } \\
\text { de lavar } \\
\text { Varal } \\
\text { suspenso } \\
\text { Tábua de }\end{array}$ & $\begin{array}{l}\text { Cama casal } \\
\text { Criado-mudo } \\
\text { Roupeiro } \\
\text { Espaço para } \\
\text { berço } \\
\text { Sapateira/cômoda }\end{array}$ & $\begin{array}{l}2 \text { camas ou } \\
\text { beliche } \\
\text { Roupeiro } \\
\text { Mesa de estudos } \\
\text { Sapateira/cômoda }\end{array}$ \\
\hline \multicolumn{6}{|c|}{ Prever área de uso do mobiliário } \\
\hline \multicolumn{6}{|c|}{ Prever faixa de circulacão livre de $90 \mathrm{~cm}$ na cozinha e $60 \mathrm{~cm}$ nos demais combartimentos } \\
\hline \multicolumn{6}{|c|}{ A sala deve ser intearada ou contíaua à cozinha } \\
\hline \multicolumn{6}{|c|}{ A área de servico deve ser contíaua à cozinha } \\
\hline \multicolumn{6}{|c|}{ Otimizar parede hidráulica entre as áreas molhadas } \\
\hline \multicolumn{6}{|c|}{ Prever portas de $80 \mathrm{~cm}$ de abertura } \\
\hline \multicolumn{6}{|c|}{ Garantir a liberacão intearal da área de varredura das portas } \\
\hline \multicolumn{6}{|c|}{ Prover espaco suficiente para abroximacão e uso do comando das ianelas } \\
\hline \multicolumn{6}{|c|}{ Todas as ianelas devem ventilar para a área externa } \\
\hline
\end{tabular}

Fonte: Autores (2019)

A qualidade do espaço da moradia está relacionada à sua adequação às necessidades de seus usuários. Para Pedro (2000, p. 9), o conceito de qualidade habitacional se refere "à adequação da habitação e de sua envolvente às necessidades imediatas e possíveis dos moradores, compatibilizando as necessidades individuais com as da sociedade". 
Frente a este conceito, portanto, ressalta-se a importância de atender aos requisitos de funcionalidade e flexibilidade da moradia, ao longo do tempo de uso e permanência.

O conceito de funcionalidade se relaciona às propriedades específicas recomendadas para que uma habitação atenda a sua finalidade frente a referências mínimas de espaço e de mobiliário e equipamentos para o uso da moradia (LEITE, 2006).

Para Palermo (2009), a funcionalidade tem a ver com a relação entre espaço, o conjunto de equipamentos necessários a cada atividade e o usuário da moradia, incluindo o acesso ao interior da casa e a cada cômodo, a circulação dentro da casa e em cada cômodo, o acesso e a operação de cada móvel ou equipamento doméstico.

A literatura aponta uma grande quantidade de diretrizes para garantia da funcionalidade na moradia, que foram sintetizadas no Quadro 1 (ABNT, 2013; PALERMO, 2009; PEDRO, 2001).

Quadro 2 - Diretrizes de flexibilidade para o projeto de HIS

\begin{tabular}{|c|}
\hline Diretrizes de flexibilidade \\
\hline Conceber diferentes plantas, compatíveis com os diferentes arranjos familiares \\
\hline Utilizar divisórias leves/removíveis ou o próprio mobiliário para a compartimentação interna \\
\hline Agrupar áreas molhadas e instalações em módulos hidráulicos ou paredes específicas \\
\hline Adotar formas neutras/padronizadas nos quartos \\
\hline Propor funções simultâneas em um mesmo compartimento (cômodo multiuso) \\
\hline Propor mais de uma disposição de layout nos cômodos secos \\
\hline Separar estrutura de vedações, preferencialmente \\
\hline Criar meios reversíveis de alterar as relações entre os compartimentos (integrar / isolar) \\
\hline Possibilitar a troca da porta do banheiro, de forma a criar suíte \\
\hline Indicar sentido(s) de expansão da unidade \\
\hline $\begin{array}{l}\text { Provisão de novo dormitório, local de trabalho ou espaço multiuso; } \\
\text { Provisão de varanda ou garagem; } \\
\text { Não trocar as esquadrias de lugar; } \\
\text { Garantir ventilação para o exterior em todos os ambientes; } \\
\text { Prever porta ou painel removível que faça ligação da área original com a área ampliada; } \\
\text { Projetar cobertura que possa ser prolongada com concordância geométrica, mantendo o pé- } \\
\text { direito mínimo. }\end{array}$ \\
\hline Prever afastamento frontal compatível com estacionamento de veículos \\
\hline
\end{tabular}

Fonte: Autores (2019)

O segundo conceito abordado nesta pesquisa, flexibilidade, inclui o potencial de realizar mudanças antes da ocupação e também de adequá-la durante o tempo de permanência ou uso. Ela pode ser estabelecida, inicialmente, como uma maneira de possibilitar ao morador a escolha do seu layout, permitindo variações dentro de uma mesma forma arquitetônica e, posteriormente, como forma de tornar possíveis mudanças futuras e adaptações necessárias, como mudar o layout interno e incrementar a moradia em termos econômicos (FINKELSTEIN, 2009; SCHNEIDER; TILL, 2007). 
Diferentes formas de aplicação da flexibilidade são elencadas na literatura, compreendendo uma grande quantidade de diretrizes de projeto que direcionam o projetista à elaboração de moradias mais flexíveis. Nesta pesquisa foram listadas no Quadro 2 aquelas que mais se adequam ao projeto sob análise, que segue a tipologia de casas em fita. Essas diretrizes foram encontradas em uma vasta revisão bibliográfica (ABREU; HEITOR, 2007; BRANDÃO, 2002, 2006; ESTEVES, 2013; FINKELSTEIN 2009; FRIEDMAN, 1997, 2002; PAIVA, 2002; PEDRO, 2000).

\section{O CASO DO PROJETO QUINTA MONROY}

O conjunto habitacional Quinta Monroy apresenta tipologia de casas em fita, com unidades térreas e duplex. A estrutura das unidades é majoritariamente de concreto, com algumas soluções em madeira - nas escadas e no mezanino da unidade duplex. Ademais, a estrutura foi pensada para sustentar as futuras ampliações.

A forma com o arquiteto projetou as habitações permitiu um controle de expansão. Sendo assim, por mais divergentes que fossem as alterações entre as residências, a obra ainda conversaria com a forma original. A expansão é permitida dentro da estrutura prevista: o térreo pode ser ampliado para a lateral e para os fundos; o duplex para as laterais, sobre a laje da unidade térrea. A Figura 1 apresenta o modelo BIM do Conjunto, desenvolvido pelos autores.

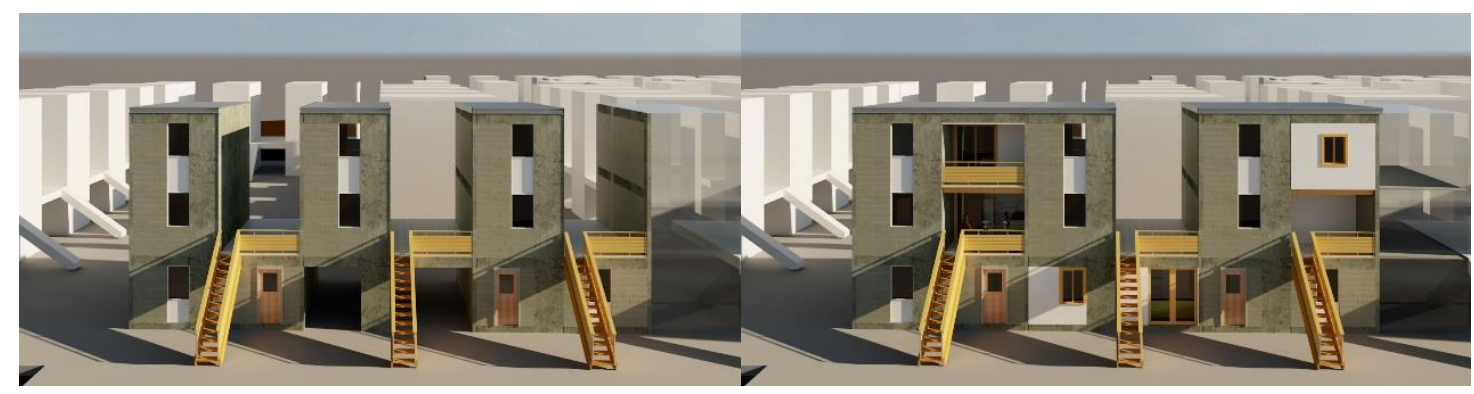

Figura 1 - Imagem do modelo Autodesk Revit 2018 do projeto Quinta Monroy do arquiteto Alejandro Aravena, antes e depois das alterações -

Fonte: Autores (2019)

As habitações foram entregues com toda a parte estrutural e de fundação, além de equipamentos básicos como banheiros, cozinhas, escadas e paredes de divisórias. Os banheiros e cozinhas foram locados de forma a facilitar as instalações hidráulicas.

A Figura 2 se refere à planta do nível térreo e é composta por seis módulos de $3 \times 6$ metros. Os módulos em amarelo foram entregues prontos, com a estrutura, vedações, janelas e portas; e os em roxo seriam finalizados pelos moradores, que seriam responsáveis pela vedação e acabamentos. As vedações demarcadas na cor preta se referem as paredes fixas inicialmente entregue aos moradores; já as vedações demarcadas na cor vermelha se referem a divisórias de fácil remoção. Na imagem, são demonstradas duas opções de layout, uma com dois dormitórios e outra com um dormitório e um comércio. 
Os mobiliários possuem linhas pontilhadas demarcando sua área de uso'. Nota-se que no quarto do casal é possível colocar um guarda-roupa, mas a área de uso e circulação seria inadequada.

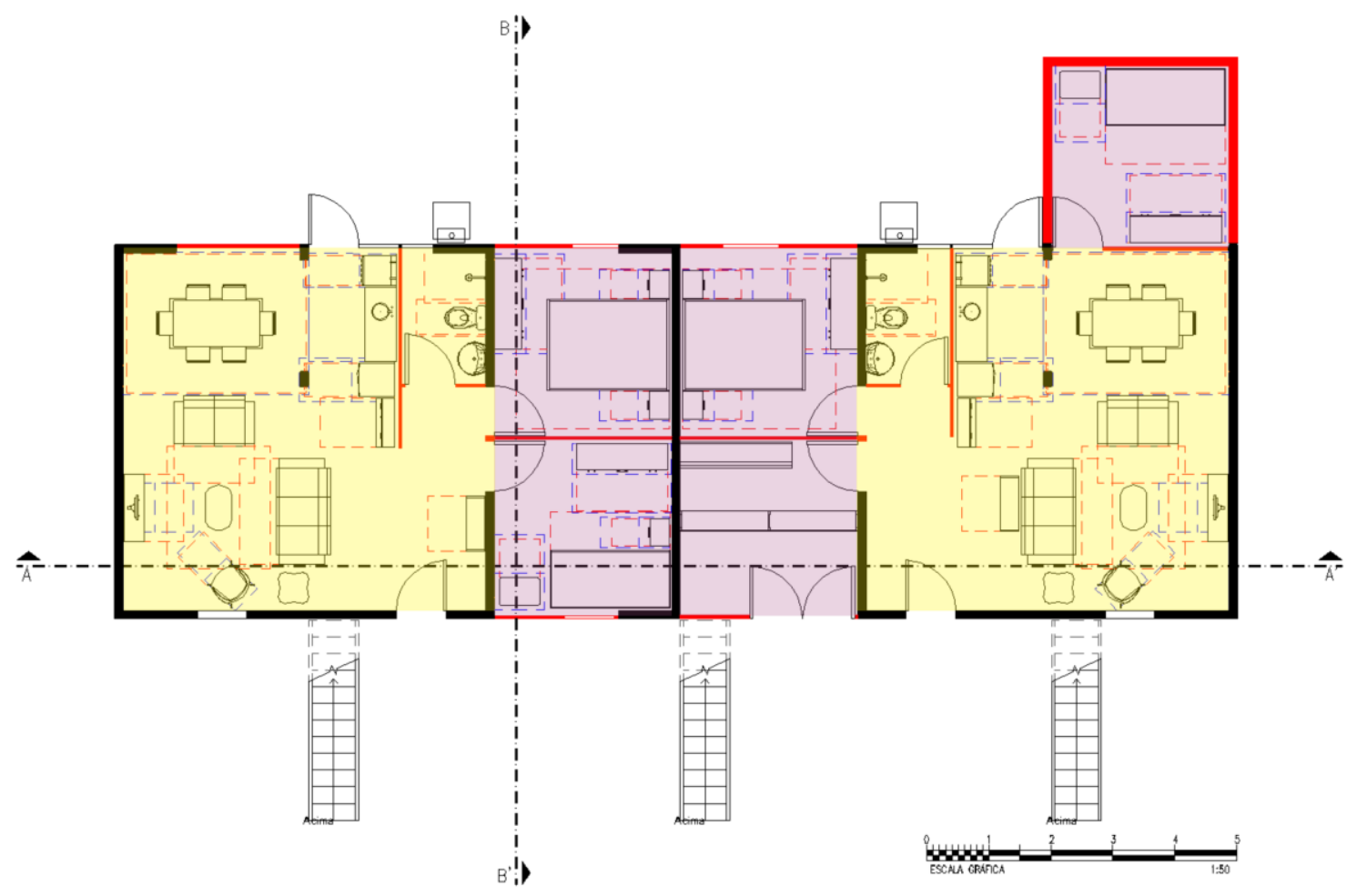

Figura 2 - Planta do nível térreo com possíveis modificações geradas no modelo BIM Fonte: Os autores (2019)

Nas unidades térreas, permitiram-se também ampliações para os fundos, como demonstrado na unidade da direita, onde um terceiro dormitório é proposto. Cabe ressaltar que a área de serviço não foi projetada como um compartimento - apenas alocou-se o tanque na parede dos fundos, pelo lado externo, e o morador poderia optar por cobrir o espaço, caso desejasse.

A Figura 3 se refere à planta do primeiro pavimento das unidades duplex. Assim como na unidade térrea, o primeiro pavimento é composto por módulos de $3 \times 6$ metros, onde as demarcações em amarelo foram entregues prontas e as demarcações em roxo foram destinadas às expansões a serem realizadas pelos moradores. Nesta figura, demonstramos 2 opções de layout, uma delas com a alocação de um pequeno comércio. Diferente da unidade térrea, que pode ser ampliada também para os fundos, a área expansível do duplex limita-se às demarcações modulares, sendo necessária a construção do mezanino e da cobertura, além das vedações. Nota-se que, salvo a cozinha, as configurações de layout podem sofrer diversas modificações, se adaptando com facilidade.

\footnotetext{
1 Utilizaram-se as famílias de mobiliário disponibilizadas por Logsdon et al. (2019).
} 


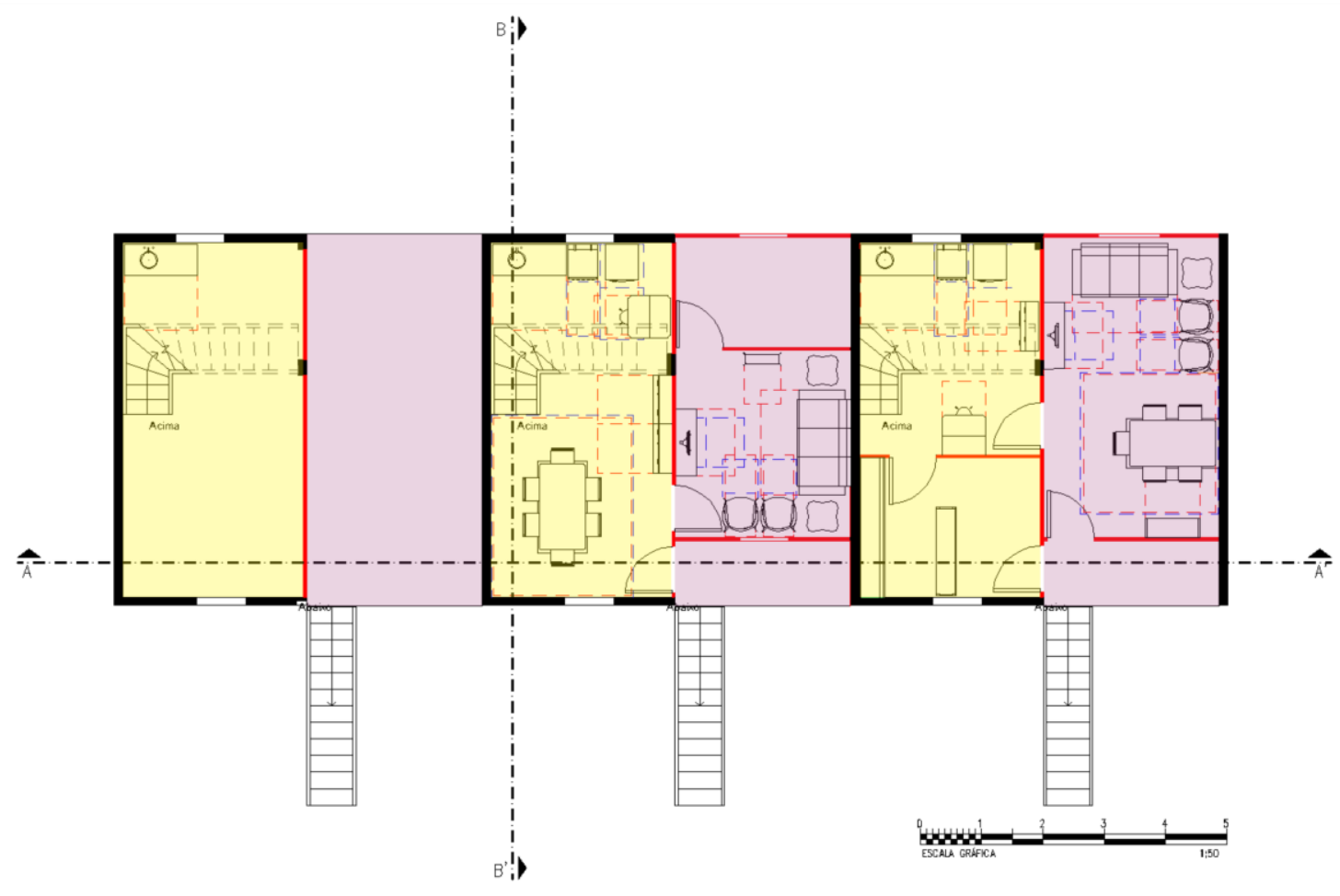

Figura 3 - Planta do primeiro pavimento que compõe as unidades duplex com possíveis modificações geradas no modelo BIM Fonte: Os autores (2019)

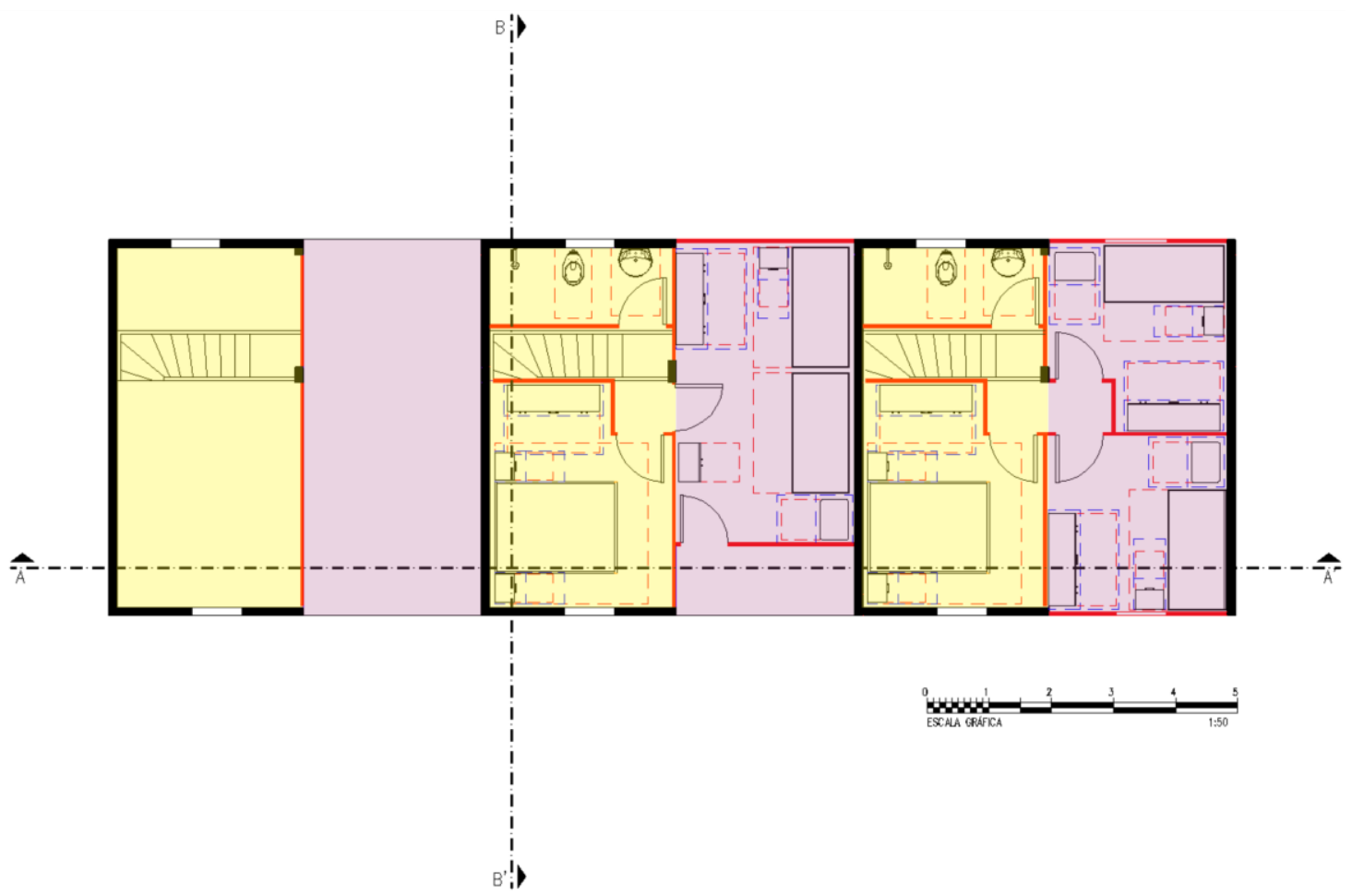

Figura 4 - Planta do segundo pavimento que compõe as unidades duplex com possíveis modificações geradas no modelo BIM - 
A Figura 4 ilustra a planta do terceiro pavimento - ou pavimento superior da unidade duplex - que possui as mesmas características da anterior. Entretanto, as opções de layout aqui apresentadas são destinadas as áreas íntimas. A posição da escada acaba sugerindo um hall de circulação, que daria acesso aos compartimentos. Nota-se que, como ocorre na planta térrea, o quarto destinado ao casal também apresenta uma área de circulação inadequada. As Figuras 5 e 6 ilustram os cortes do modelo.

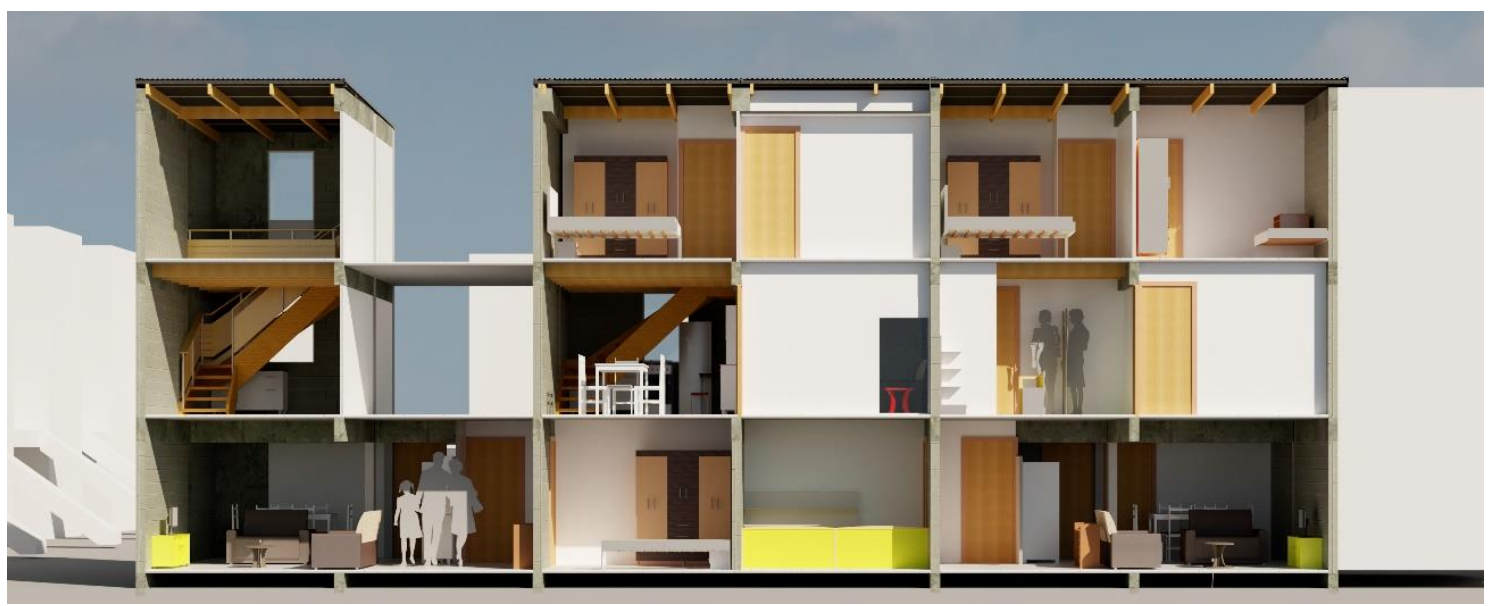

Figura 5 - Corte longitudinal AA' -

Fonte: Os autores (2019)

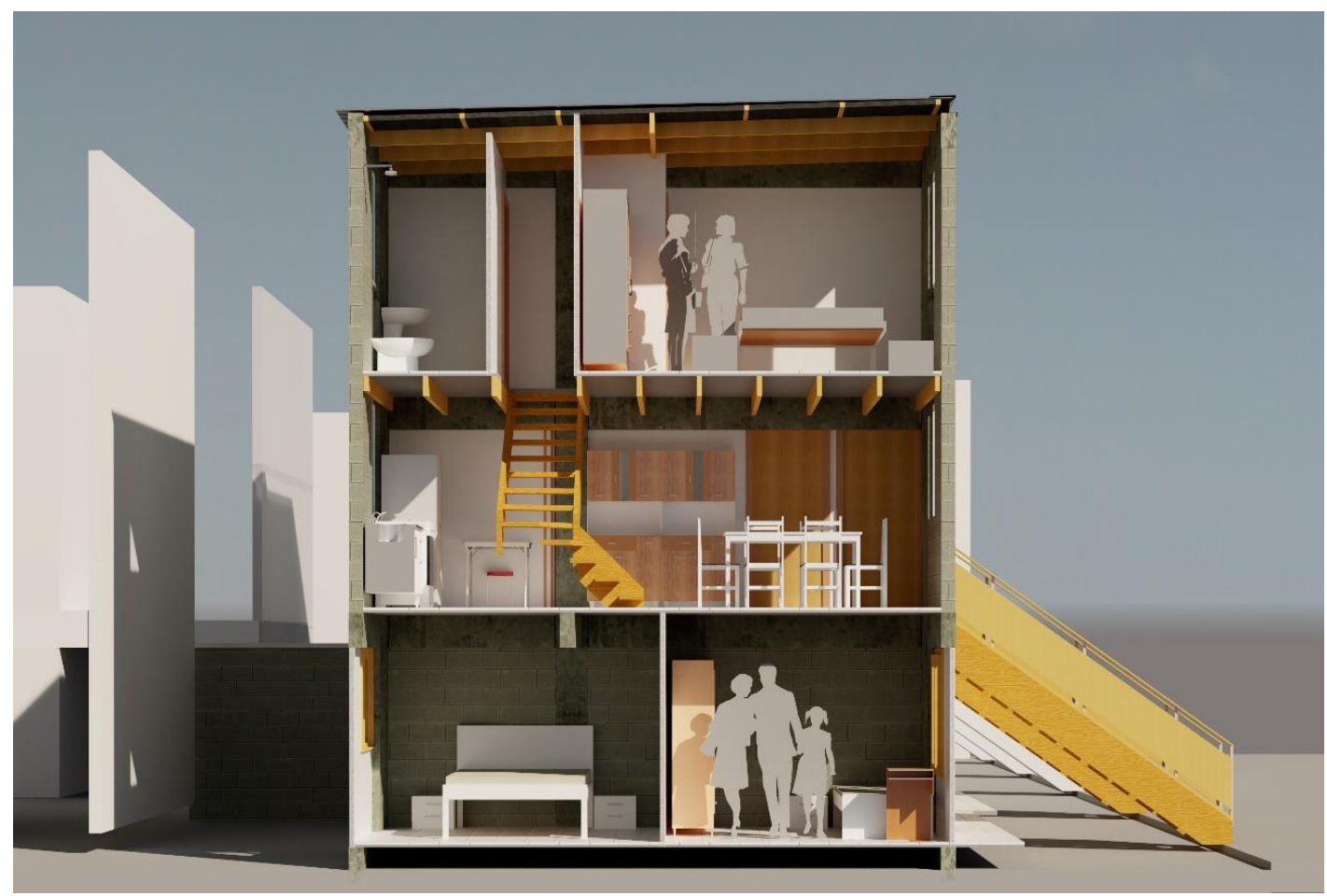

Figura 6 - Corte transversal BB' -

Fonte: Os autores (2019)

Uma característica de uma moradia flexível é a separação da estrutura e dos elementos de vedação, o que ocorre no projeto, como é possível verificar nas Figuras 5 e 6. Outra característica notável no projeto de Aravena, que pode ser observada tanto nas plantas apresentadas (Figuras 2 a 4) quanto no corte 
transversal BB' (Figura 6), é a otimização das paredes hidráulicas, o que é recomendado para agregar flexibilidade ao projeto, além da otimização de recursos.

Desta maneira, segue abaixo uma síntese da análise espacial do projeto Quinta Monroy com base nos princípios levantados sobre funcionalidade e flexibilidade nas unidades habitacionais (Quadro 3).

Quadro 3 - Análise do projeto frente aos requisitos de funcionalidade e flexibilidade

\begin{tabular}{|c|c|c|c|}
\hline \multirow{12}{*}{ 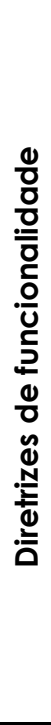 } & \multirow{2}{*}{$\begin{array}{l}\text { Diretrizes } \\
\text { Mobiliário mínimo }\end{array}$} & \multicolumn{2}{|c|}{ Quinta Monroy } \\
\hline & & (1) & $\begin{array}{l}\text { Possui, exceto da área de serviço e } \\
\text { quarto de casal. }\end{array}$ \\
\hline & Área de uso do mobiliário & $\checkmark$ & Possui em ambas configurações. \\
\hline & Faixa de circulação livre & $\checkmark$ & Possui em ambas configurações. \\
\hline & Sala integrada ou contígua & $\checkmark$ & Possui em ambas configurações. \\
\hline & Área de serviço contígua a cozinha & $x$ & Não possui área de serviço \\
\hline & Otimizar parede hidráulica & $\checkmark$ & Sim, em ambas configurações. \\
\hline & Portas de $80 \mathrm{~cm}$ de abertura & $\checkmark$ & Sim, em ambas configurações. \\
\hline & Área de varredura das portas & $\checkmark$ & Sim, em ambas configurações. \\
\hline & Espaço para uso das janelas & $\checkmark$ & Sim, em ambas configurações. \\
\hline & Janelas ventilando para área externa & $\checkmark$ & Sim, em ambas configurações. \\
\hline & Pé direito mínimo para cômodos & (1) & Majoritariamente $\operatorname{sim}^{2}$. \\
\hline \multirow{14}{*}{ 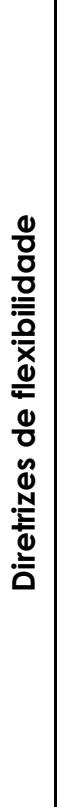 } & Conceber diferentes plantas & $\checkmark$ & Sim, em ambas configurações. \\
\hline & Divisórias leves/removíveis & $\checkmark$ & Sim, em ambas configurações. \\
\hline & Agrupar áreas molhadas & $\checkmark$ & Sim, em ambas configurações. \\
\hline & Formas neutras nos quartos & $\checkmark$ & Sim, em ambas configurações. \\
\hline & Cômodo multiuso & $\checkmark$ & Sim, em ambas configurações. \\
\hline & Cômodos secos com mais de um layout & $\checkmark$ & Sim, em ambas configurações. \\
\hline & Separar estrutura de vedação & $\checkmark$ & Sim, em ambas configurações. \\
\hline & Alterar relações entre repartições & $\checkmark$ & Sim, em ambas configurações. \\
\hline & Troca da porta do banheiro (suíte) & $\boldsymbol{x}$ & Não possui \\
\hline & Janelas padronizadas & $\checkmark$ & Sim, em ambas configurações. \\
\hline & Indicar sentidos de expansão & $\checkmark$ & Sim, em ambas configurações. \\
\hline & Plantas com as futuras ampliações & $\checkmark$ & Sim, em ambas configurações. \\
\hline & Afastamento para estacionamento & $\boldsymbol{x}$ & Não possui \\
\hline & Manual do usuário da habitação & $\checkmark$ & Possui \\
\hline
\end{tabular}

Fonte: Os autores (2019)

Segundo a matéria publicada em 2016 na revista aU | Arquitetura e Urbanismo em 2016, o professor Patricio Hiche exprime a história e a opinião dos moradores sobre a habitação do conjunto Quinta Monroy. De acordo com

2 O Quinta Monroy tem pé-direito de 2,20m em todos os ambientes. Esta dimensão é menor ao que é exigido no Brasil, mas acredita-se que esteja coerente às normas do Chile. 
uma das entrevistadas, que residia no assentamento anterior ao projeto do arquiteto Alejandro Aravena, um dos pontos notáveis do conjunto fora a participação da comunidade durante a etapa de desenho. Tomás Cortese, arquiteto coordenador do Escritório Elemental, reafirma que esse era o pontochave do projeto, algo que promoveu uma maior diversidade no processo de ocupação de cada pátio do terreno. O projeto Quinta Monroy não foi apenas uma construção habitacional, foi um processo de readequação social de famílias que, possivelmente, pela primeira vez receberiam um endereço postal. A configuração tipológica das edificações e o agrupamento delas em um conjunto de pátios, onde todas as unidades dão acesso à rua, se mostrou como uma excelente distribuição no terreno, que priorizou o convívio comunitário. Os moradores puderam escolher, inclusive, os membros que compunham essas unidades de vizinhança formadas ao redor de cada pátio (HICHE, 2016).

A configuração das edificações afastou-se de uma tipologia que era rejeitada pelos moradores - o bloco de habitação coletiva. No entanto, continua sendo uma estrutura solidária em que a modificação de uma unidade afeta todo o conjunto. Haveria, portanto, uma necessidade de monitoramento sobre as intervenções de cada morador, para resguardar a integridade da edificação, o que pressupõe a organização de comitês associados a alguma instituição que pudesse fazer as fiscalizações. Isso não aconteceu e, naturalmente, a individualidade de cada família impulsionou, muitas vezes, ampliações que excederam os limites propostos pelo projeto (HICHE, 2016).

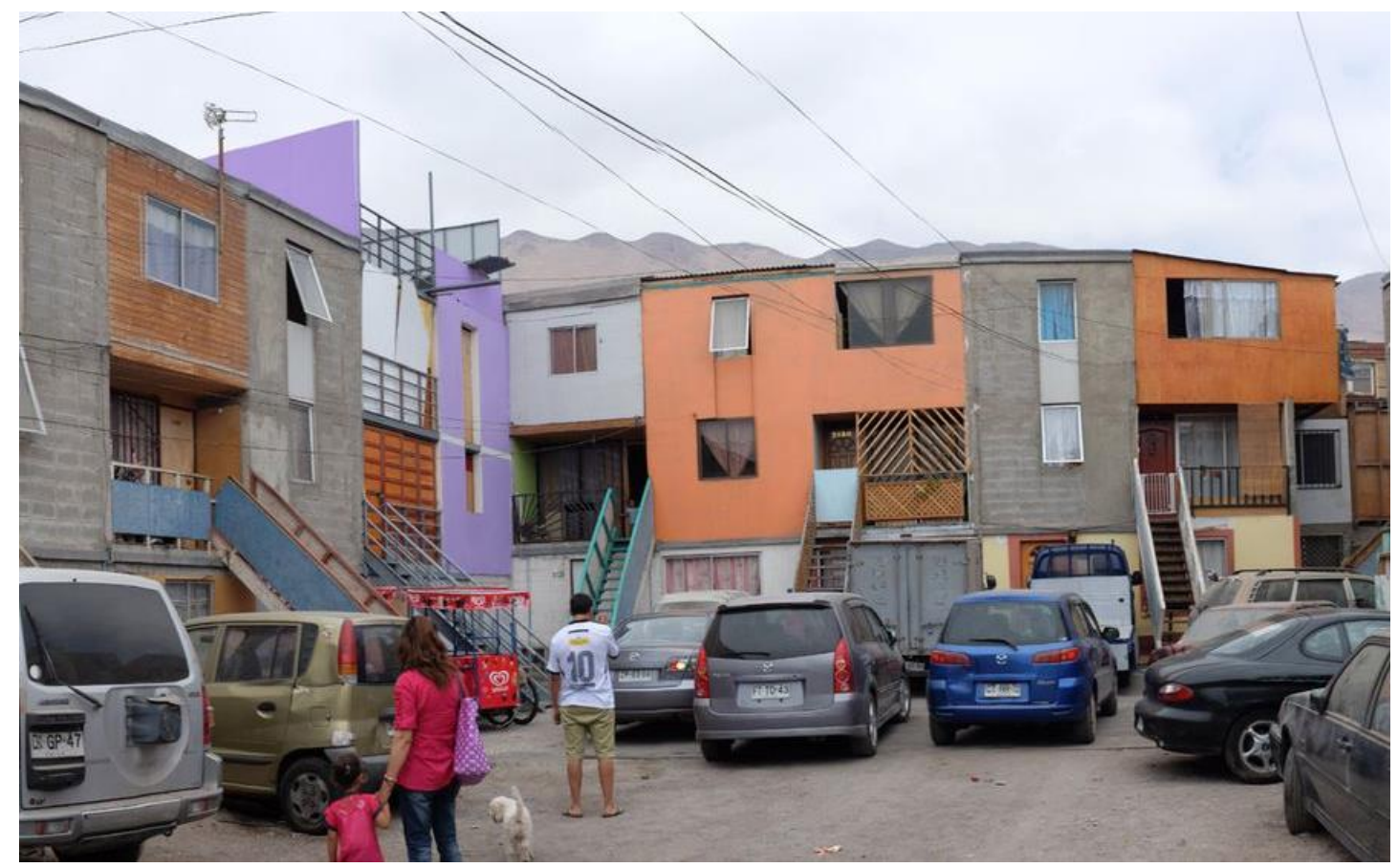

Figura 7 - Pátios internos do conjunto habitacional Quinta Monroy

Fonte: Amiee Groundwater (2015)

Outra questão que pode ser observada atualmente no conjunto é a forma como foi apropriado os pátios internos. Inicialmente, estes foram pensados como um lugar de encontro e recreação, mas, com a melhoria na qualidade de vida, surgiu a necessidade de um espaço para alocar os automóveis. 
Sendo assim, os espaços originalmente definidos como coletivos, hoje são definidos como estacionamentos.

\section{CONSIDERAÇÕES FINAIS}

Esta pesquisa originou-se a partir de um projeto de iniciação científica que tinha como objetivo explorar a modelagem BIM de alguns projetos premiados de HIS. O processo de modelagem contribuiu não só para o conhecimento relacionado ao BIM e às ferramentas de modelagem - no caso o software Autodesk Revit 2019 -, mas também para a análise espacial dos projetos modelados. Através da interação com as demais pesquisas realizadas no grupo de pesquisa (Arquitec IAU-USP), teve-se acesso às famílias de mobiliário e sistemas construtivos modeladas, bem como às teorias de qualidade espacial na habitação - dentre elas, a funcionalidade e a flexibilidade.

Frente a isso, a pesquisa ampliou-se para a análise do projeto aqui explorado - Quinta Monroy. Ressalta-se que não foi viável, dentro dos limites desta pesquisa, envolver uma avaliação pós-ocupação (APO) que incluísse o levantamento das ampliações, reformas e apropriações realizadas pelos moradores, por exemplo. Algumas informações quanto à satisfação dos moradores foram obtidas em sites de arquitetura, como apresentadas ao fim do terceiro capítulo, mas seria interessante desenvolver pesquisas futuras neste sentido.

Acredita-se, portanto, que os resultados obtidos por este estudo podem contribuir com pesquisas dentro do tema de habitação social, da mesma forma que o modelo BIM do Quinta Monroy - disponibilizado para download no site do Arquitec IAU-USP (https://arquitec.iau.usp.br/produção/bibliotecabim) - pode auxiliar estudantes tanto no entendimento do projeto quanto no desenvolvimento de outros modelos BIM.

\section{AGRADECIMENTOS}

Ao Conselho Nacional de Desenvolvimento Científico e Tecnológico (CNPq) e ao Instituto Federal de Educação, Ciência e Tecnologia de Mato Grosso (IFMT), pelo apoio recebido.

\section{REFERÊNCIAS}

ABREU, R.; HEITOR, T. Estratégias de Flexibilidade na arquitetura doméstica holandesa: da conversão à multifuncionalidade. Infohabitar, 122. Disponível em: <http://infohabitar.blogspot.com.br/2007/01/estratgias-de-flexibilidadena.html>. Acesso em: 04 out. 2019.

ASSOCIAÇÃO BRASILEIRA DE NORMAS TÉCNICAS (ABNT). NBR 15.575-1. Edifícios habitacionais - Desempenho. Parte 1: Requisitos Gerais. Rio de Janeiro: ABNT, 2013.

AU I ARQUITETURA E URBANISMO (PINIWEB). Chileno Alejandro Aravena, de 48 anos, vence o Prêmio Pritzker de Arquitetura 2016. Jan. 2016. Disponível em: <http://aul 7.pini.com.br/arquitetura-urbanismo/arquitetos/chileno-alejandroaravena-de-48-anos-vence-o-premio-pritzker-367432-1.aspx>. Acesso em: 18 fev. 2019. 
BRANDÃO, D. Q. Diversidade e potencial de flexibilidade de arranjos espaciais de apartamentos: uma análise do produto imobiliário no Brasil. Tese (Doutorado em Engenharia de Produção) - Universidade Federal de Santa Catarina, Florianópolis, 2002.

Habitação Social evolutiva: aspectos construtivos, diretrizes para projetos e proposição de arranjos espaciais flexíveis. Cuiabá: CEFET-MT, 2006.

CONTROLADORIA-GERAL DA UNIÃO (GOVERNO FEDERAL). Minha Casa Minha Vida: $\mathbf{5 6 , 4 \%}$ dos imóveis avaliados apresentam defeitos na construção. Ago. 2017. Disponível em: <http://www.cgu.gov.br/noticias/2017/08/minha-casaminha-vida-56-4-dos-imoveis-avaliados-apresentam-defeitos-na-construcao>. Acesso em: 12 fev. 2019

ESTEVES, A. M. C. Flexbilidade em arquitetura: um contribuição adicional para a sustentabilidade do ambiente construído. Dissertação (Mestrado Integrado em Arquitectura - dARQ) - Universidade de Coimbra, Coimbra, 2013.

FINKELSTEIN, C. W. Flexibilidade na Arquitetura Residencial - um estudo sobre o conceito e sua aplicação. Dissertação (Mestrado) - Universidade Federal do Rio Grande do Sul, Porto Alegre, 2009.

FRIEDMAN, A. Adaptable house - Designing Homes for Change. New York: McGraw-Hil, 2002.

HICHE, P. M. Quinta Monroy 12 anos depois: uma análise da habitação social de alejandro aravena. 2016. REVISTA AU | ARQUITETURA E URBANISMO.

Disponível em: <https://au.pini.com.br/2016/03/quinta-monroy-12-anos-depoisuma-analise-da-habitacao-social-de-alejandro-aravena/>. Acesso em: 13 maio 2019.

JARDIM, M. C. Habitação (é) Elemental: o caso de Quinta Monroy. In: Anais do Fórum Habitar. Belo Horizonte(MG) UFMG, Jan. 2018. Disponível em: $<$ https//www.even3.com.br/anais/habitar/72537-HABITACAO-(E)-ELEMENTAL-O-CASO-DE-QUINTA-MONROY>. Acesso em: 18 fev. 2019.

LEITE, L. C. R. Avaliação de projetos habitacionais - avaliando a funcionalidade da moradia social. São Paulo: Ensino Profissional, 2006.

PAIVA, A. L. S. A. Habitação flexível - Análises de conceitos e soluções. Dissertação (Mestrado em Arquitetura da Habitação) - Faculdade de Arquitectura da Universidade Técnica de Lisboa, Lisboa, 2002.

PALERMO, C. Sustentabilidade Social do Habitar. 1. ed. Florianópolis: Da autora, 2009.

PEDRO, J. B. Definição e avaliação da qualidade habitacional. Tese (Doutorado em Arquitectura) - Universidade do Porto, Portugal., 2000.

Programa Habitacional: Habitação. 4a. ed. Lisboa: Laboratório Nacional de Engenharia Civil, 2001. v. 1. 